\title{
Ildikó Andó
}

\section{Individual Values for Organizational Success}

Douglas MCGregor published Theory $Y$ in 1960. The main element of his theory is integration of individual and organizational objectives. Today, near 50 years later, the integration of individual and organizational goals remains only theory in several business organizations.

The author of this study conducted an online survey in 2008 in order to examine company cultures, values and leadership attitudes in Hungarian organizations. One of the cultural elements studied by the survey was harmonization between organizational-level and individual-level sets of values. Two multinational companies with 324 respondents took part in the research up to this time. This publication shows the findings of the survey and illustrates the importance of harmonization between organizational-level and individual-level values. Finally it comes up with some ideas what leaders can do in order to harmonize the value hierarchies efficiently in their organizations.

JEL classification index: D21, L21, L25

Keywords: company culture, organizational-level values, individual-level values, harmonization of sets of values, empowerment

\section{Individualism versus Collectivism}

Organizational values are fundamental elements of a company culture. As Gyökér says organizational culture is a soft dimension of the company which influences on business performance significantly. Organizational culture can be identified as a system of norms based on common values, beliefs and standards of behavior. (Gyökér 2001)

Values appear at two main levels in organizations. One of them is the level of the whole organization and the other one is the level of the individuals. According to Borgulya and Barakonyi collectivist cultures focus on organizational-level values against individual creativity and self-actualization. By contrast, individualist cultures concentrate on individual-level values creating a competitive work environment. (Borgulya - Barakonyi 2004)

Hofstede and Trompenaars approach Individualism and Collectivism as two opposite poles of the same cultural dimension. According to Geert Hofstede employees in an individualist culture are expected to act according to their own interests and work should

The autor is a human consultant at Budapest University of Technology and Economics, e-mail: ando.jldiko@kalidon.hu 
be organized in such a way that this self-interest and the employer's interest coincide. By contrast employees in a collectivist culture will act according to the interest of the group which may not always coincide with the interest of the individuals. (Hofstede - Hofstede 2005)

Fons Trompenaars defines the cultural dimensions as Individualism versus Communitarianism. In an individualistic culture people place the individual before the community. In a communitarian culture people place the community before the individual. (Trompenaars - Hampden-Turner 2006) Both models emphasize the role of the values in forming and developing organizational cultures.

Researches by Hofstede and Trompenaars identified Hungarians as individualist. GLOBE's Hungarian researchers published the same result. (Bakacsi et al. 2002)

As it can be seen several researchers treat individualism and collectivism as opposite poles of the same cultural element. By contrast, Riddersttrale and Nordstrom say that people are individualists and team players at the same time. The company of the future is neither individualist nor collectivist, but both of them together. Organization is a group of strong personalities united by common objectives. (Ridderstrale - Nordstrom 2006)

Researchers have been interested in harmonization between organizational-level and individual-level values for many decades. Douglas McGregor in 1960 gave the title of his publication: "Theory Y: the integration of individual and organizational goals". According to McGregor the theory of integration means to make conditions in which the employees can accomplish their individual goals most successfully by means of making their efforts for the objectives of the company. Most successfully means, that the alternatives of selfmotivation and self-control are more attractive than any other possibilities such as neglectfulness, irresponsibility and hostility. The managers preferring theory Y motivate their subordinates continuously to improve and harness their knowledge, practice, abilities and creativity for the success of the company. (McGregor 1960)

Lovey and Nadkarni write in their book titled "The Joyful Organization" that the more possibilities the organization provides for the person for self-actualization and for development of his competencies, the stronger belongingness he feels to the company. Furthermore they say if the employees have to be able to reach not only the goals of the organization but also their individual aims then both the company and the individual become successful. The healthy organization fulfills the needs of its employees by creating an atmosphere in which the members of the group improve their competencies, they feel important and they can achieve their purposes while they realize organizational objectives. (Lovey - Nadkarni 2003)

\section{Four-dimension model of empowerment}

This study is based on the four-dimension model of empowerment. The author of this paper integrated the results of Hungarian and international researches of organizational culture and empowerment into the four-dimension theory. The model consists of the following elements of empowerment:

- Creating an atmosphere of trust

- Harmonizing sets of values
- Willingness to take responsibility for decisions

- Working in network (Ando 2008)

Knowing that world-famous gurus, like Douglas McGregor, Kenneth Blanchard, Chris Argyris, Kjell A. Nordstrom, Jonas Ridderstrale, Imre Lovey and Manohar Nadkarni have researched the delegation of making decisions for many decades and they have published their results in several books and articles, the question arises, why a Hungarian person makes efforts to develop a special approach in the same field. Firstly, the existing models of empowerment are based on US and Western-European corporate cultures. It is an unquestionable fact that these cultures differ significantly from the Hungarian culture, which is burdened among others by the legacy of the former communist regime. Secondly, western theories and practices presume an empowering business culture, where the leaders are ready to give the right of decision to their subordinates and subordinates are ready to make decisions.

Although several Hungarian managers spend a lot of time and money to improve their competencies in delegation and empowerment most of them are not ready to delegate and empower today. Moreover, the operation of Hungarian organizations is based on rules and regulations rather than empowerment. Consequently, the first task of Hungarian managers is to establish preconditions for an empowering corporate culture. For these reasons, modern western models cannot be applied to the empowerment issues in Hungarian companies because they are beyond the establishment of an empowering company culture.

This paper studies the second dimension of empowerment model: harmonization of sets of values. In order to create empowering atmosphere leaders have to achieve harmonization between organizational-level and individual-level values. Harmonization doesn't mean that the value hierarchies at the level of organization and individuals have to be the same from value to value. Harmonization means coincidence in priorities of sets of values, as well as that the leaders and their subordinates are ready to appreciate the differences between their value hierarchies mutually.

What is the role of harmonization of sets of values in empowerment and in the success of a company? According to Kenneth Blanchard, empowerment means giving the right of decision making to autonomous teams and employees. In empowerment leaders don't control the decision making process of their subordinates continuously. (Blanchard Carlos - Randolph 1998) Lovey and Nadkarni write in their book that if you are guided by clear vision and internal norms the worry about the lack of control disappears. (Lovey - Nadkarni 2003)

An empowering leader sleeps like a baby because he is sure that decisions of their empowered employees are based on harmonized values and common goals. As a result, the continuous control is not necessary. Blanchard says in his book that the way of decision making become simpler by clearing the values because everybody can start with common ground. (Blanchard - Carlos - Randolph 1998)

In an empowering organizational culture leader relies on the professional know-how of his employees and employees trust in the leadership know-how of their leader. The mutual trust is crucial in empowerment because the problems which empowered employees have to solve are new and sophisticated. For this reason, employees have to use their professional intuition to find solution for the problems. As the leader doesn't have to have professional 
intuition and he is not able to be always then and there when and where the decisions are made, he has to trust in the professional know-how of his subordinates. The mutual trust is essential to harmonization between sets of values. Harmonization in turn develops the mutual trust between leaders and their employees.

In this study the harmonization of sets of values is examined as a dimension of empowerment. However harmonization between organizational-level and individual-level values has strong effect on business success regardless of empowerment. Business success is supported by performance of individuals. Individuals improve their performance, if they are motivated internally. Internal motivation or self-motivation means that employees do their job outstandingly because they can achieve their individual goals in this way. Outstanding performance is crucial for accomplishment of business objectives. In order for employees to be able to fulfill their individual goals in their job the leaders have to take individual-level values of their colleagues into consideration. If the leaders realize that individual-level values are as important as organizational-level values for business success they would make efforts to harmonize them with each other.

Gyökér summarizes the elements of organizational cultures supporting the outstanding performance:

- Trust in and respect to the leaders

- Being convinced that organizational objectives are valuable

- Fulfillment with job

- The feeling that fulfillment has strong connection to performance of the group

- General experience that the leaders' main objective is to satisfy the needs of employees

(Gyökér 2001)

\section{Methods of the survey}

The author of this study conducted on online survey in 2008. The main topics of the survey were business cultures, sets of values and leadership attitudes focusing on empowerment Present publication shows the part of the survey regarding sets of values. The aim of the examination of sets of values was to obtain answers to the following questions:

- What are the organizational value hierarchies of Hungarian companies?

- What are the individual value hierarchies of the employees in Hungarian companies?

- Whether are the organizational-level values and individual-level values harmonized in Hungarian companies?

- To what extent are the organizational-level values and individual-level values harmonized in Hungarian companies?

Two multinational companies joined the survey up to this time. The studied companies are signed Company " $\mathrm{A}$ " and Company " $\mathrm{B}$ ". Company " $\mathrm{A}$ " is a multinational service corporation in financial sector with more than two thousands employees. 300 people from the organization were invited to the survey. The response rate was 71 percent, with 214 respondents. Company " $\mathrm{B}$ " is also a multinational corporation in the industrial sector with more than five thousands employees. 187 people from a service unit of the organization were invited to the survey. The response rate was 59 percent, with 110 respondents.
Altogether 314 respondents sent back completed questionnaires, which made it possible to perform a statistical analysis.

Before the survey the author defined the circle of the studied values. For this reason she analyzed the vision and the organizational values of twenty multinational business companies working in Hungary. Dominant company values connected to the four dimensions of the empowerment model were selected for the survey. As a result of the analysis 10 main values were identified.

In the first part of the survey regarding harmonization of sets of values the respondents had to answer the question:

- "How often can be the values experienced in action at your company?"

The rating scale ranged from 1, "value is always experienced" to 7 , "value is never experienced".

Organizational-level values were following:

- Mutual trust between leaders and their subordinates

- Result-orientation

- Recognition for performance

- Involvement into decision making processes

- Development of employees' competencies

- Creativity in problem-solving

- Open and honest communication

- Knowledge sharing

- Free flow of information

- Co-operation in problem-solving

In the second part of the survey regarding harmonization of sets of values respondents had to rank the individual-level values from $1_{2}$ "the most important value" to 10 , "the least important value" answering the question:

- "How important are the values in your job?"

- Individual-level values were following:

- Mutual trust between my leaders and me

- Result-orientation in my job

- Recognition of my performance

- My involvement into the decision making processes

- Development of my competencies

- Application of my creativity in problem-solving

- Honest communication in my job

- The possibility for knowledge sharing

- Availability of necessary information for my job

- Co-operation in problem-solving in my job

In order to examine the harmonization of sets of values organizational-level and individuallevel value hierarchies consist of the same elements. Company-level values were mapped by the analysis of responses for the first question. Individual-level values were examined by the study of the answers for the second question. After completion of both the companylevel and the individual-level sets of values they were compared with each other and it was evaluated whether they are harmonized or not, and if yes, than to what extent they are harmonized. 


\section{Results of the analysis}

Concerning the examination of harmonization between organizational-level and individual-level values the author set up three hypotheses. This part of present publication represents the findings of the survey by evaluation of the hypotheses. As far as the analysis and consequences are concerned it has to be mentioned that validation of the hypotheses requires involvement of further companies into the survey.

\section{Organizational level values}

Hypothesis 1. There is no significant difference between the organizational-level sets of values in the two participating companies.

Based on findings of GLOBE survey in Hungary, Bakacsi and his team divided Hungarian companies into four cultural clusters. The first cluster includes state companies with large power distance and low performance-motivation. The second cluster consists of organizations which are characterized by strong future-orientation and high uncertainty avoidance. The third cluster is defined with extremely large power distance, significant individualism and low human- and performance-orientation. The fourth cluster is described as collectivist with high human-orientation and small power distance. According to the findings of Hungarian GLOBE survey, there is no direct relationship between clusters and the core activities of the companies. One cluster can contain companies from financial industrial, health sectors, as well as information and telecommunication areas. (Bakacsi Takács 1998)

As far as the two participating companies are concerned on the one hand there are several similarities between them. They are big multinational companies with strong Hungarian management, and the economic and political changes at the end of $20^{\text {th }}$ centuries affected them considerably. On the other hand there is a main difference between them. One of them is a Hungarian company and the other one is a subsidiary of a European corporation. In spite of the difference it can be assumed, that their cultures developed in almost paralle way, because their Hungarian managers taught at the same business schools and trainings, they worked with the same consultancies, and they work under the same economic circumstances.

In order to justify Hypothesis 1 the author carried out a statistical analysis. As it was mentioned earlier, the measurement of organizational-level values was conducted on the Likert scale with seven ordered response levels. The author calculated statistical means for every organizational-level values. In order to examine the relation between sets of values and companies she used Student's t- test. By means of t-test she could validate, whether the null hypothesis, that the means of the two independent populations (Company " $\mathrm{A}$ " and Company " $\mathrm{B}$ ") are different, is acceptable or not. She conducted a t-test on every organizational-level values in the two companies. As a result of the analysis the calculated p-values were below 0.05 (chosen threshold for statistical significance) in the case of co-operation, development and creativity. It means that it is unlikely the possibility of differences in response patterns between Company " $\mathrm{A}$ " and Company " $\mathrm{B}$ " was obtained by chance. For the rest of the organizational-level values it cannot be excluded that the possibility of differences between the statistical means occurred by chance for the two participating companies.
Besides t-test the author performed a Pearson's Chi-square test to examine whether the distributions of the two independent samples are homogenous or not. For every cultural element the calculated Chi-square statistics were less than Chi-square possibility at the 0.05 significance level. Based on the results of Chi-square test the distributions of samples could be identified as homogenous for every organizational-level values.

As far as the intervals of statistical means for the 10 organizational-level values are concerned, it could be found that they were absolutely short for both companies. The length of the interval is 1,3 for Company " $A$ " and it is 1,14 for Company " $B$ ". As it was mentioned, the responses were measured on the rating scale ranged from 1 to 7 .

Table 1

\section{t-test for organizational-level values}

\begin{tabular}{|c|c|c|c|c|c|c|}
\hline & $\begin{array}{l}\text { Mean } \\
\text { Company } \\
\text { „A" }\end{array}$ & $\begin{array}{c}\text { Mean } \\
\text { Company } \\
\text { „B" }\end{array}$ & $\mathrm{t}$-value & $\mathrm{p}$ & $\begin{array}{c}\text { Std.Dev. } \\
\text { Company } \\
{ }_{n} A^{n}\end{array}$ & $\begin{array}{c}\text { Std.Dev. } \\
\text { Company } \\
\text { „B" }\end{array}$ \\
\hline Co-operation & 2,9252 & 2,6545 & $-2,2942$ & 0,0224 & 1,0228 & 0,9715 \\
\hline Creativity in problem-solving & 3,2430 & 2,9545 & $-2,2628$ & 0,0243 & 1,1452 & 0,9615 \\
\hline Development of competencies & 3,3178 & 3,0091 & $-2,2945$ & 0,0224 & 1,1473 & 1,1454 \\
\hline Free flow of information & 3,4299 & 3,3636 & $-0,5173$ & 0,6053 & 1,1015 & 1,0728 \\
\hline Honest communication & 3,5374 & 3,4091 & $-0,8760$ & 0,3817 & 1,2657 & 1,2138 \\
\hline Involvement into decision & 3,2056 & 3,0455 & $-1,2671$ & 0,2060 & 1,0898 & 1,0526 \\
\hline Knowledge sharing & 3,2804 & 3,3364 & 0,4406 & 0,6598 & 1,0373 & 1,1674 \\
\hline Mutual trust & 3,0794 & 3,1636 & 0,6977 & 0,4859 & 1,0293 & 1,0274 \\
\hline Recognition for performance & 3,6028 & 3,5909 & $-0,0993$ & 0,9210 & 1,0099 & 1,0431 \\
\hline Result-orientation & 2,3084 & 2,4455 & 1,0974 & 0,2733 & 1,0651 & 1,0630 \\
\hline
\end{tabular}

Calculated p-values were below 0.05 for the cultural elements with bold characters.

Additionally, examining the value hierarchy in the two participating corporations we could see that the first two values and the last three values are the same in the order The intervals of statistical means between third and seventh positions are really short: 0,24 for Company " $\mathrm{A}$ " and 0,38 for Company " $\mathrm{B}$ ". These extremely brief intervals cannot make significant differences be detected among the organizational-level cultural elements possible.

Although the findings of the survey don't explain the cause of the differences in value hierarchies of the companies, we can take some consequences. Firstly, as both corporations are multinational business companies it could be predicted that the most experienced value in action is result-orientation. 
Chi-square-test for organizational-level values

\begin{tabular}{lccc} 
& $\begin{array}{c}\text { Pearson Chi- } \\
\text { square }\end{array}$ & df & p \\
\cline { 2 - 4 } Co-operation & 7,1743 & 4 & 0,1270 \\
Creativity in problem-solving & 7,8022 & 6 & 0,2530 \\
Development of competencies & 8,2726 & 6 & 0,2188 \\
Free flow of information & 3,3163 & 5 & 0,6513 \\
Honest communication & 2,7478 & 6 & 0,8398 \\
Involvernent into decision & 3,9283 & 5 & 0,5598 \\
Knowledge sharing & 9,2814 & 5 & 0,0984 \\
Mutual trust & 6,5458 & 5 & 0,2567 \\
Recognition for performance & 5,7859 & 6 & 0,4476 \\
Result-orientation & 2,0545 & 5 & 0,8415
\end{tabular}

Secondly, it is also not surprising that the co-operation is in high position of value hierarchies. High position of co-operation is in line with findings of other parts of the survey. When the author studied the three further elements of empowerment model (mutual trust, willingness to take responsibility and working in network) by the survey, she found that building networks was the most efficient dimension in operation at both companies. Building networks has strong connection to co-operation. Networks can be built by co-operation of employees inside and outside their business units.

\section{Value hierarchies for organizational-level values}

Company „A”.

\begin{tabular}{ccc} 
Company „A” & \multicolumn{1}{c}{ Company „B” } \\
\hline Result-orientation & 1 & Result-orientation \\
Co-operation & 2 & Co-operation \\
Mutual trust & 3 & Creativity in problem-solving \\
Involvement into decision & 4 & Development of competencies \\
Creativity in problem-solving & 5 & Involvement into decision \\
Knowledge sharing & 6 & Mutual trust \\
Development of competencies & 7 & Knowledge sharing \\
Free flow of information & 8 & Free flow of information \\
Honest communication & 9 & Honest communication \\
Recognition for performance & 10 & Recognition for performance
\end{tabular}

Thirdly, regardless of the organization, respondents experience information sharing, communication and recognition for performance in action most rarely. Consequently the question raises, how successful a result-oriented company can be if it really recognizes the performance of their employees.

In sum it can be stated that t-test, Chi-square test and interval examinations support Hypothesis 1, that there is no significant differences between organizational-level value hierarchies in the two participating companies.

Table 1 and Table 2 represent the results of statistical hypothesis tests. Table 3 shows the value hierarchies for organizational-level values at Company " $\mathrm{A}$ " and Company " $\mathrm{B}$ ".

\section{Individual-level values}

Hypothesis 2. There is no significant difference between the individual-level sets of values in the participating companies.

Both Hungarian and international researchers have examined organizational cultures with several methods and questionnaires based on several scientific models for many decades. By contrast the comparison the organizational-level values with individual-level values in business world is not an extensively examined and published research theme. GLOBE research mapped experienced and expected level of Hofstede's cultural dimensions in Hungarian companies. But GLOBE concentrated only on organizational values. This study tries to evaluate individual-level values in a simple way.

Table 4

$t$-test for individual-level values

\begin{tabular}{cccccc}
$\begin{array}{c}\text { Mean } \\
\text { Company } \\
\text { A }\end{array}$ & $\begin{array}{c}\text { Mean } \\
\text { Company } \\
\text {,B" }\end{array}$ & 1-value & $p$ & $\begin{array}{c}\text { Std.Dev. } \\
\text { Company } \\
\text { „A" }\end{array}$ & $\begin{array}{c}\text { Std.Dev. } \\
\text { Company } \\
\text {,B” }\end{array}$ \\
\hline 4,7523 & 4,8455 & $-0,3057$ & 0,7600 & 2,5801 & 2,6273 \\
6,0514 & 6,1545 & $-0,3302$ & 0,7415 & 2,7291 & 2,5276 \\
7,0935 & 6,8182 & 0,9804 & 0,3276 & 2,4362 & 2,3075 \\
4,8178 & 4,7455 & 0,2242 & 0,8227 & 2,7407 & 2,7642 \\
4,3224 & 4,6727 & $-1,0976$ & 0,2732 & 2,6930 & 2,7731 \\
5,9813 & 5,7818 & 0,6930 & 0,4888 & 2,3991 & 2,5572 \\
6,4159 & 6,8091 & $-1,2808$ & 0,2012 & 2,5892 & 2,6699 \\
3,9393 & 4,6182 & $-1,8815$ & 0,0608 & 3,0228 & 3,1767 \\
5,9159 & 5,5273 & 1,1512 & 0,2505 & 2,8749 & 2,8821 \\
5,7103 & 5,0273 & 1,8736 & 0,0619 & 3,0335 & 3,2466
\end{tabular}

Similarly to Hypothesis 1, in the case of examination of Hypothesis 2 the author also used Student's t-test in order to define whether the possibility of differences between average ranks of individual-level values in the participating companies occurred by chance or not. 
Firstly she calculated the average ranks of individual-level values for both corporations Using a t-test she could decide, whether the null hypothesis, that the average ranks of two independent samples (Company "A" and Company "B") are statistically different or not. She conducted t-test on every individual-level values. As a result of the analysis the calculated p-values were below 0.05 (chosen threshold for statistical significance) for every individual cultural elements. It means that it cannot be excluded the possibility of differences in response patterns between Company " $\mathrm{A}$ " and Company " $\mathrm{B}$ " was obtained by chance.

Similarly to organizational-level values the author conducted a Pearson's Chi-square test to examine whether the distributions of the two independent samples are homogenous or not. The results were parallel with those in the earlier situation. In the case of every cultural element the calculated Chi-square statistics were less than Chi-square possibility at the 0.05 significance level. Chi-square test validated that the distributions of samples could be identified as homogenous for each individual-level value.

\section{Chi-square-test for individual-level values}

\begin{tabular}{cccc} 
& $\begin{array}{c}\text { Pearson Chi- } \\
\text { square }\end{array}$ & df & $\mathrm{p}$ \\
\cline { 2 - 4 } Co-operation & 6,4426 & 9 & 0,6949 \\
Creativity in problem-solving & 13,2276 & 9 & 0,1526 \\
Development of competencies & 7,9309 & 9 & 0,5411 \\
Free flow of information & 2,2943 & 9 & 0,9859 \\
Honest communication & 9,2508 & 9 & 0,4145 \\
Involvement into decision & 3,2534 & 9 & 0,9534 \\
Knowledge sharing & 6,5545 & 9 & 0,6844 \\
Mutual trust & 13,0717 & 9 & 0,1594 \\
Recognition for performance & 3,9902 & 9 & 0,9121 \\
Result-orientation & 8,7918 & 9 & 0,4567
\end{tabular}

Examining the interval of ranks it can be claimed that the interval (I) of individual values was longer for Company " $A$ " $\left(I_{A}=3,15\right)$ than that for Company " $B$ " $\left(I_{B}=2,2\right)$. The difference between the lengths of intervals can be interpreted that the respondents from Company " $A$ " distinguished the importance of values in their job more sharply, than the respondents from Company " $\mathrm{B}$ ". But it is only one among the possible explanations and at this level of study it is not justified.

Beyond the statistical results the survey produced an unexpected outcome. The sequences of individual-level values are almost the same for both participating companies. There is only one exchange in the third and the fourth positions regarding co-operation and free flow of information. The survey doesn't reveal the origin of this phenomenon.
If we study the individual-level value hierarchies, we can find that mutual trust is of high importance not only regarding empowerment but also in everyday relationship between the leaders and their subordinates. The fact that respondents took the mutual trust at the first place of the hierarchies indicates that the individual sets of values provide empowerment with solid basis.

In sum both t-test and Chi-square test support Hypothesis 2, that there is no significant difference between the sequences of individual-level values in the two participating companies.

\section{Value hierarchies for individual-level values}

Table 6

\begin{tabular}{ccc} 
Company „A" & \multicolumn{2}{c}{ Company „B" } \\
\hline Mutual trust & 1 & Mutual trust \\
Honest communication & 2 & Honest communication \\
Co-operation & 3 & Free flow of information \\
Free flow of information & 4 & Co-operation \\
Result-orientation & 5 & Result-orientation \\
Recognition for performance & 6 & Recognition for performance \\
Involvement into decision & 7 & Involvement into decision \\
Creativity in problem-solving & 8 & Creativity in problem-solving \\
Knowledge sharing & 9 & Knowledge sharing \\
Development of competencies & 10 & Development of competencies
\end{tabular}

Table 4 and Table 5 represent the results of statistical hypothesis tests. Table 6 shows the value hierarchies for individual-level values at Company " $\mathrm{A}$ " and Company " $\mathrm{B}$ ".

\section{Harmonization between sets of values}

Hypothesis 3. The organizational-level and individual-level sets of values are not harmonized in the participating companies.

Douglas McGregor wrote in 1960 , that Theory X companies are managed autocratically. Theory $\mathrm{X}$ organizations don't consider the goals and needs of individuals. Theory $\mathrm{X}$ managers tend to believe in rigid hierarchical structure with narrow span of control at every level of the organization. Theory X managers rely heavily on threat and constraint to gain their employee's compliance. By contrast, Theory $Y$ managers believe that their employees are ambitious, self-motivated and exercise self-control. Theory $\mathrm{Y}$ managers make effort to integrate organizational and individual goals because they rely that this is an efficient way to strengthen motivation and to develop performance. 
Lovey and Nadkarni wrote in 2003 , that an organization can become healthy and joyful if it fulfills the needs of employees. By contrast, people think that the role of a leader is to give priorities and to persuade employees to do according to these priorities. The primary objective of a company is to satisfy the needs of customers and organization. These aims are more important than the fulfillment of the needs of employees, because accomplishment of primary objectives is tangible in short period against intangible effects of satisfaction of the needs of employees. (Lovey - Nadkarni 2003) The authors give severa ideas to the leaders how they can make their organization joyful and healthy. Today it can be claimed that in several companies the employees - leaders and their subordinates together - have to make efforts to harmonize the organizational-level and individual-level value hierarchies.

Comparison of organizational-level and individual-level value hierarchie Company "A"

\begin{tabular}{ccc} 
Organizational-level value hierarchy & & Individual-level value hierarchy \\
\hline Result-orientation & 1 & Mutual trust \\
Co-operation & 2 & Honest communication \\
Mutual trust & 3 & Co-operation \\
Involvement into decision & 4 & Free flow of information \\
Creativity in problem-solving & 5 & Result-orientation \\
Knowledge slaring & 6 & Recognition for performance \\
Development of competencies & 7 & Involvement into decision \\
Free flow of information & 8 & Creativity in problem-solving \\
Honest communication & 9 & Knowledge sharing \\
Recognition for performance & 10 & Development of competencies
\end{tabular}

Differently from the earlier two hypotheses, in the third case statistical methods are not used to justify Hypothesis 3 . The cause of this approach originates from the methods of measurement. The ways of measurement of organizational-level and individual-level values were different. Respondents measured organizational-level cultural elements on the Likert scale with seven ordered response levels. In the case of individual-level yalues respondents had to rank the 10 cultural elements. According to the standards of questionnaires if you want to map the importance of positive elements from the viewpoint of respondents, the Likert scale is not the best solution. If somebody ask you to define how important the 10 examined cultural elements are in your job, it is most likely that your answer would be "very important" for every values. Getting a great deal of "very important" answers the statistical analysis wouldn't be efficient. In similar situations ranking is a successful way to analyze the data. (Babbie 1998)
Comparison of organizational-level and individual-level value hierarchies Company "B"

\begin{tabular}{ccc} 
Organizational-level value hierarchy & & Individual-fevel value hierarchy \\
\hline Result-orientation & 1 & Mutual trust \\
Co-operation & 2 & Honest communication \\
Creativity in problem-solving & 3 & Free flow of information \\
Development of competencies & 4 & Co-operation \\
Involvement into decision & 5 & Result-orientation \\
Mutual trust & 6 & Recognition for perlormance \\
Knowledge slaring & 7 & Involvement into decision \\
Free flow of information & 8 & Creativity in problem-solving \\
Honest communication & 9 & Knowledge slaring \\
Recognition for performance & 10 & Development of competencies
\end{tabular}

Ranking is an excellent tool if you want to map the hierarchy of individual values. But if you ask the respondents to rank organizational-level values focusing how often values can be experienced at the company, than you get a relative scale, but you don't gain information about the frequency of the values in action.

In spite of the different methods of measurement the author could evaluate the harmonization between organizational-level and individual-level values using the calculated value hierarchies.

Firstly, there is a substantial difference at the first place of the value scales. In both companies the most frequent organizational-level value in action is result-orientation. Regarding the individual sets of values the mutual trust takes the first position for both corporations. Secondly, while the honest communication and information sharing are the eighth and ninth positions in organizational value hierarchies, same cultural elements take the second and third/fourth places among the individual-level values. Thirdly, recognition for performance takes up the last position in organizational-level value hierarchies. Recognition for performance is the sixth value in the sequence of individual-level cultural elements.

Besides the main differences there is another interesting phenomenon in individuallevel value hierarchies. Respondents evaluated knowledge sharing and development of competencies as the least important individual values. The survey doesn't explain this phenomenon. It can be interpreted in such a way, that respondents evaluated not only the importance of the values but perhaps the availability of them at the companies. According to this approach it can be presumed that employees gain new professional knowledge at trainings, workshops and conferences. But this explanation is not justified at this level of the survey. 
The identified significant differences between organizational-level and individual-level value hierarchies support Hypothesis 3 that the present organizational and individual sets of values are not harmonized at the two participating companies.

Table 7 and Table 8 represent the comparisons between organizational-level and individual-level values at Company " $\mathrm{A}$ " and Company " $\mathrm{B}$ ".

\section{Harmonization for business success}

This study represented the importance of harmonization between organizational-level and individual-level values. The survey resulted, that sets of values at the two participating companies are not harmonized at this time. The question comes what leaders can do for harmonization.

The first leadership tool is the open and honest communication. As Blanchard says, a company doesn't have any organizational values unless its employees believe, accept and adopt the basic principles. People in the organizations often cannot imagine how differently they experience the values of the company. (Blanchard - Carlos - Randolph 1998)

Ridderstrale and Nordstrom emphasize that during recruitment process leaders have to focus not on capabilities but on individual values. The half-life of knowledge is extremely short in several industries. But if we want to hire employees concentrating on their attitudes we have to make our values absolutely clear. (Ridderstrale - Nordstrom 2006)

Additionally, communicating organizational values is not enough. Leaders have to do their job according to these values. Employees have to experience organizational values not only in documents and in speeches but mainly in the actions of their leaders.

Besides making organizational values clear the leaders have to make efforts to know the individual values of their employees. Individual values play crucial role in internal motivation. As Chris Argyris says in his publication empowerment can work and performance can arise only by internal motivation. (Argyris 1999) If the leaders are not aware which values are important for their subordinates they are not able to motivate them. One of the efficient tools for motivation is to harmonize organizational-level values with individual-level values, because employees enjoy consideration of their leaders and they feel really important in this way.

If the leaders and their subordinates know each other's value hierarchies, they have to strive to harmonize them. Leaders have to consult the actions for harmonization with their subordinates. According to the findings of the survey information sharing, communication and recognition for performance have to be strengthened in both participating companies. Presumably if these cultural elements become stronger, mutual trust could take higher position in organizational value hierarchies and result-orientation could take more important position in individual sets of values.

If the leaders' willingness to share knowledge and information becomes stronger then it is likely that their attitude to communication changes in a positive way in parallel. Honest communication and sharing knowledge and information strengthen mutual trust between leaders and their subordinates. The developing mutual trust inspires employees to reveal their personal values even if these personal values don't coincide with the organizational values completely. Consequently, the harmonization of sets of values makes the development of empowering business culture possible significantly.

The leaders, who are motivated to harmonize sets of values both internally and externally, become ready to focus on individual-level values of their employees. Knowing the dominant values of their subordinates, leaders will be efficient in motivating them. If the leaders inspire their employees successfully the employees would improve their performance dramatically. Furthermore, if the leaders recognize the outstanding performance of their colleagues, both business objectives and individual goals could be accomplished.

Finally, based on the results of previous international researches and the present survey it can be claimed that harmonization between organizational-level and individual-level values have a positive relationship with business success evidentially.

\section{References}

Andó Ildikó (2008): Úton a felhatalmazás felé. CEO Magazin, No. 4:21-26.

Argyris, C. (1999): Az alkalmazottak felhatalmazása: a császár úi ruhája. Harvard Business Manager No. 1:39-46.

Bakacsi Gyula - Takács Sándor (1998): Honnan - Hová? A nemzeti és szervezeti kultúra változásai a kilencvenes évek közepének Magyarországán. Vezetéstudomány, No. 2:15-22.

Bakacsi et al. (2002): Bakacsi Gyula - Takács Sándor - Karácsonyi András - Imrek Viktor, V.: Eastern European cluster: tradition and transition. Journal of World Business, 69-80.

Blanchard, K. - Carlos, P. J. - Randolph, A. (1998): Empowerment - A felelösség hatalma. Budapest, SHL Hungary.

Borgulya István - Barakonyi Károly (2004): Vallalati kultúra, Stratégiaalkotás III. Nemzeti Tankönyvkiadó, Budapest.

Earl Babbie (1998): A társadalomtudományi kutatás gyakorlata. Balassi Kiadó, Budapest.

Gyökér Irén (2001): Szervezeti viselkedés. MBA jegyzet, BME, Budapest.

Hofstede, G. - Hofstede, G. J. (2005): Cultures and Organizations. McGraw-Hill, NewYork. Lovey, I. - Nadkarni, M. S. (2003): Az örömteli szervezet. HVG Kiadói Rt., Budapest.

McGregor, D. (1960): The Human Side of Enterprise. McGraw-Hill, NewYork.

Ridderstrale, Jonas - Nordstrom, Kjell A. (2006): Karaoke kapitalizmus. Akadémiai Kiadó, Budapest.

Trompenaars, F. - Hampden-Turner, C. (2006): Riding the Waves of Culture. Nicholas Brealey Publishing, London. 